\title{
Optimization of detection of single line to ground fault by controlling peterson coil through ANFIS
}

\author{
Feryal Ibrahim Jabbar'1, Dur Muhammad Soomro², Adnan Hasan Tawafan ${ }^{3}$, Mohd Noor bin \\ Abdullah $^{4}$, Nur Hanis binti Mohammad Radzi ${ }^{5}$, Mazhar Hussain Baloch ${ }^{6}$ \\ ${ }^{1,3}$ Department of Electric Power, Al-Furat Al-Awsat Technical University, Iraq \\ ${ }^{2,4,5}$ Department of Electrical Power Engineering, FKEE, Universiti Tun Hussein Onn Malaysia, Malaysia \\ ${ }^{6}$ Department of Electrical Engineering, Mehran University Engineering SZAB Campus Khairpur, Sindh, Pakistan
}

\section{Article Info}

Article history:

Received Feb 28, 2020

Revised Apr 27, 2020

Accepted May 11, 2020

\section{Keywords:}

Artifical neural network

Distribution

Fuzzy logic

MATLAB

PID control

\begin{abstract}
The most common fault in the distribution network is the single line to ground fault (SLGF). With earthling in the distribution network, it causes electrical arc as well as a high voltage in the faulted phase compared to other two healthy phases. It increases the danger of separation and isolation in the power network. One of the classical technique to control the arc is through Peterson Coil (PC), which detects and turns off/reduces the electrical arc making the network safer, increasing its reliability and device's safety. To control the PC, some of the techniques used in this research area are PID, FL, NN etc. This paper presents Adaptive Neural-Fuzzy Inference System (ANFIS) technique to controlling the PC. It gives the best results by detecting the fault, reducing the electrical arc and minimizing the fault current to the rated current in a very short time. Moreover, this research focuses on suppressing fault current by looking at its higher and lower peaks. Also, it calculates the opposing inductance to compensate the capacitance caused. It will save thousands of tons of copper costs. This research was conducted using MATLAB. For the validity of the proposed technique results, PID control technique was used.
\end{abstract}

This is an open access article under the CC BY-SA license.

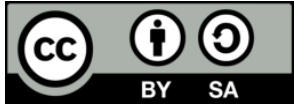

\section{Corresponding Author:}

Feryal Ibrahim Jabbar,

Department of Electric Power,

Al-Furat Al-Awsat Technical University, Iraq.

Email: inbferyal@atu.edu.iq

\section{INTRODUCTION}

Most common fault in the distribution network is the single line to ground fault (SLGF). It is reported to be almost $70 \%$ of the total faults. This one gives rise to a big problem when the residual current resulting from the intermittent electrical arc causes overvoltage twice the phase-to-phase voltage compared to two healthy phases. This is dangerous to the loads connected to it, as well as for the network isolators, as protection activates [1-5]. Moreover, the ground fault current is approximately three times the rated current compared to other two sound phases [6-10]. For this massive amount of current, an additional copper wire is needed to bear and protect the equipment, which is impossible. Therefore, the neutral point is earthed by using Peterson coil (PC) which turns off current by suppressing the electrical arc to compensate for the residual current.

There are certain classical as well as heuristic/novel techniques to detect and control the arc. These techniques include wavelet, time-frequency method, PID, FL, PID+FL, NN, and ABC [11-20]. However, artificial neural-fuzzy inference systems (ANFIS) reduces this massive current to less than the 
rated current $[8-11,21]$. Therefore, this paper presents detection of SLGF and its self-extinguishing by using ANFIS to controlling the PC in the distribution network. It is a method that combines the neural network and fuzzy logic controller. This method possesses certain advantages of auto training without a database, no distortion and very smooth too. The reason for using ANFIS is that, normally the fuzzy logic control system is non-linear, but when using, it converts to linear. The ANFIS training, testing, and validation is compared with PC, PID classical techniques [20, 22-24].

Moreover, we could achieve the main objective of this research and able to detect and adjust the fault current without electrical power outage to the consumer and thus by reducing the requirement of enormous amount of copper [2, 16, 21].

\section{METHODOLOGY}

\subsection{Distribution network}

The structural concept of the test case was taken from the IEEE distribution system $[4,12,25]$ as shown in oneline diagram (OLD) in Figure 1. However, its parameter values are replaced with real system i.e. of Babylon power grid in Iraq.

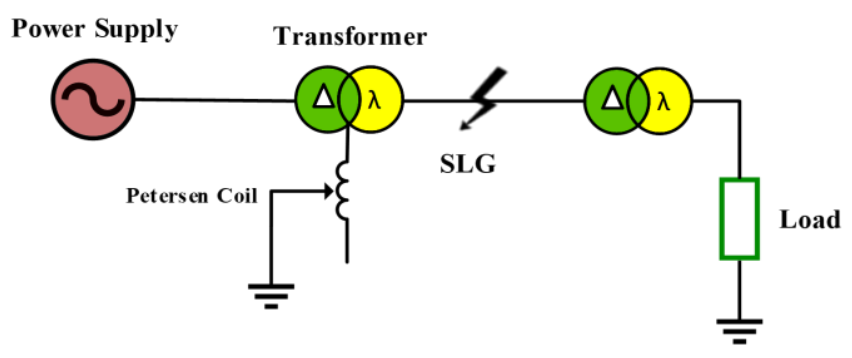

Figure 1. OLD showing SLGF and its protection by using PC

It consists of the IEEE distribution system with a programmable voltage source, 33/11 $\mathrm{kV}$ three-phase main transformer feeding three feeder loads (i.e. series RLC Y-connected loads) through three-phase four-wire system. Each of the 3-phase load is connected through three single-phase transformers. The winding connections of these transformers are:

Primary: (ABC terminals), Yg

Secondary: (abc terminals), Yn

The measurement of the three-phase voltage and current was carried out on the secondary side of the main transformer to detect its behavior during a fault condition.

\subsection{Fault conditions}

1. Symmetrical faults [2-8]:

- $\quad$ Three phase short circuit (L-L-L) (@ 5\%)

- $\quad$ Three phase to ground fault (L-L-L-G) (@ 5\%)

2. Un Symmetrical faults [5, 7-10]:

- SLGF (@70\%-80\%)

- $\quad$ Two phase short circuit (L-L) (@ 10\%)

- $\quad$ Two phase to ground fault (L-L-G) (@ 15\%)

This paper focuses on discovering the detection and remedial of an electrical arc and fault current during SLGF. When a phase-to-earth fault occurs in a three-phase grounded system, the phase voltage of the faulty phase is reduced to the earth's potential as the capacitance of the faulty line is discharged at the fault location. In contrast, the phase-to-earth voltage of the other two phases rises by $\sqrt{3}$ times, as equated below.

$$
I_{R}=I_{Y}=\frac{\sqrt{3} V_{p h}}{X_{C}}
$$

A charging current " $\mathrm{I}$ " " is developed between phase-to-earth capacitances, which continues to flow via the fault path and remains there until it is discharged. In the isolated distribution system, $\mathrm{I}_{\mathrm{C}}$ is the discharging current due to capacitance $\left(C_{R}=C_{Y}=C_{0}\right)$ of the healthy phases; meanwhile $C_{0}$ is the zero 
sequence capacitance for the line live phase. Similarly, the zero-sequence current for the fault phase is $\mathrm{C}_{\mathrm{F} 0}$. During SLGF on phase B, the system behavior will be as given in Figure 2 [2-4] and equated in (2).

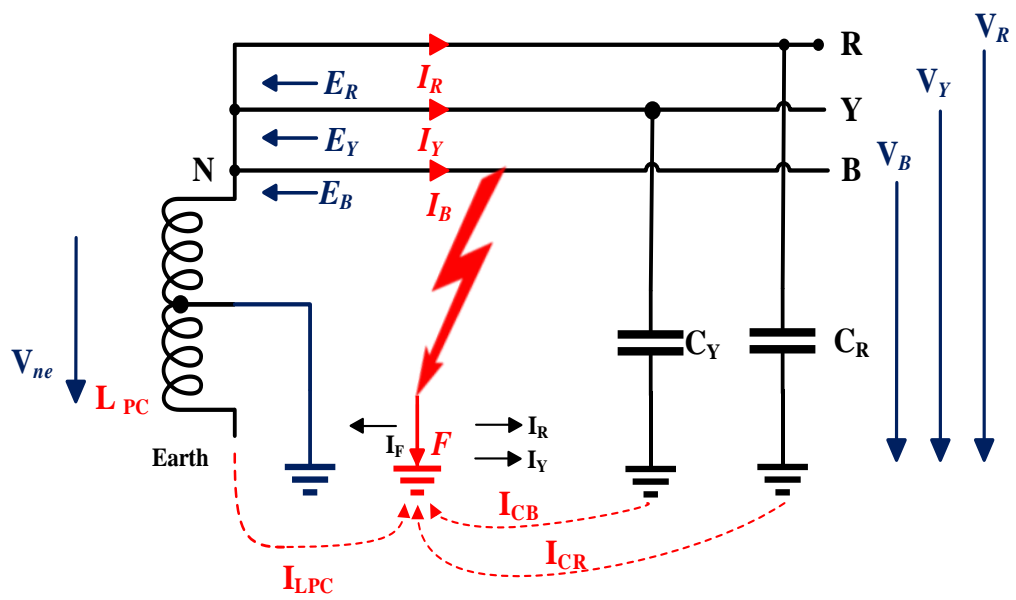

Figure 2. Behavior of the system during SLGF

$$
I_{C}=\sqrt{3} I_{R}=\sqrt{3} \times \frac{\sqrt{3} V_{p h}}{X_{C}}=\frac{3 V_{p h}}{X_{C}}
$$

Here, $X_{C}$ is the line to ground capacitive reactance of the arc suppression coil [5]. Also, fault current is given by:

$$
I_{F}=\frac{V_{p h}}{X_{L}}
$$

While, resonant grounding is

$$
I_{L}=I_{C}
$$

Therefore,

$$
\begin{aligned}
& \frac{V_{p h}}{X_{L}}=\frac{3 V_{p h}}{X_{C}} \\
& \text { Or } X_{L}=\frac{X_{C}}{3}
\end{aligned}
$$

Here, $X_{L}$ is the inductive reactance of the arc suppression coil [5]. Equation (4) can also be written as;

$$
L=\frac{1}{3 \omega^{2} C}
$$

Similarly, from (3):

$$
I_{C}=3 I=3 \frac{V_{p h}}{X_{C}}=3\left[\frac{v_{p h}}{1 / \omega C}\right]=3 \omega V_{p h}
$$

During SLGF, the zero sequence current, $I_{0 P C}$, flows to ground through PC $[1,5]$ as equated below.

$$
I_{0 P C}=j \omega U_{0} C_{0 s}
$$

Where;

$U_{0}=$ Zero sequence voltage 
$C_{0 s}=$ Total or sum of all zero sequence capacitances

Therefore, this $I_{0 P C}$ depends on the PC inductive reactance, $X_{P C}$, which implies that upon changing $L$, the $I_{0 P C}$ can be controlled.

Since $I_{F}$ is three times of the rated current [5-7], we have.

$$
I_{F}=3\left[I_{0}-I_{0 P C}\right]
$$

\subsection{Classification of grounding system and control}

The design of the grounding system could vary greatly depending on the situation, application, and geography of the site. The classification of the ground system with respect to the operating voltage of the system and the choice of method of grounding depends on many factors; including size of the system, system voltage and scheme of the protection to be used [4-5], as shown in Figure 3.

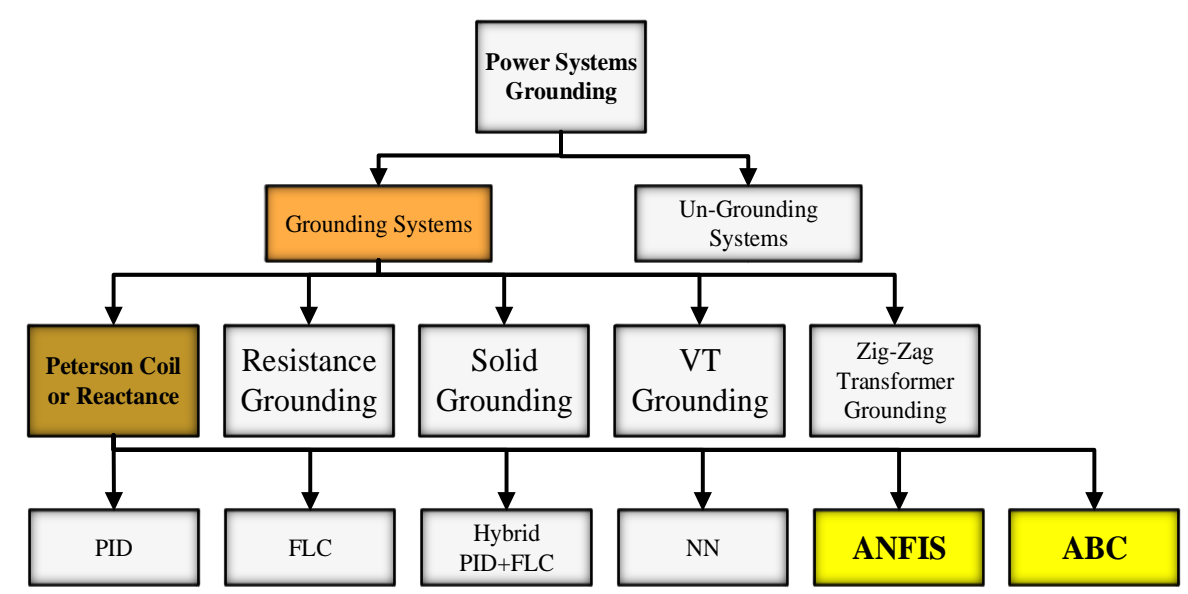

Figure 3. Classification and control of Grounding System

\subsection{Adaptive Neural-Fuzzy Inference System (ANFIS)}

Neural networks are composed of simple elements operating in parallel. The connection between elements mainly determine the network function. A neural network can be trained to perform a particular task by a modifying the values of the connection weights between the elements [3,5]. ANFIS is a class of adaptive networks equivalent to the fuzzy inference system (FIS), which represents the Sugeno fuzzy model. Tuning the network equivalent to the FIS, represents the Sugeno fuzzy design. The determination of the most suitable ANFIS model structure is based on this framework, which starts with data pre-processing by eliminating the data with missing values and the assigning of censorship (event status) after the period of study. Convert each crisp input variable into a membership grade based on the membership function defined, and fuzzy logic process performs the fuzzy inference processes. Data replication is carried out until the time an event is used, where the result is estimated. ANFIS also uses a hybrid learning algorithm, i.e. Sugeno model, if the FIS has two inputs " $x$ " and " $y$ " and one output " $z$ " $[5-7,13]$ as shown in Figure 4. A first-order Sugeno fuzzy model possesses rules $[2,4]$ as given below:

Rule1: If $x$ consists of $A_{1}, B_{1}, \ldots$ then $f_{1}$

$$
f_{1}=p_{1} x+q_{1} y+r_{1}
$$

Rule2: If $\mathrm{y}$ is $\mathrm{A}_{2}$ and $\mathrm{B}_{2}$, then $\mathrm{f}_{2}$

$$
f_{2}=p_{2} x+q_{2} y+r_{2}
$$




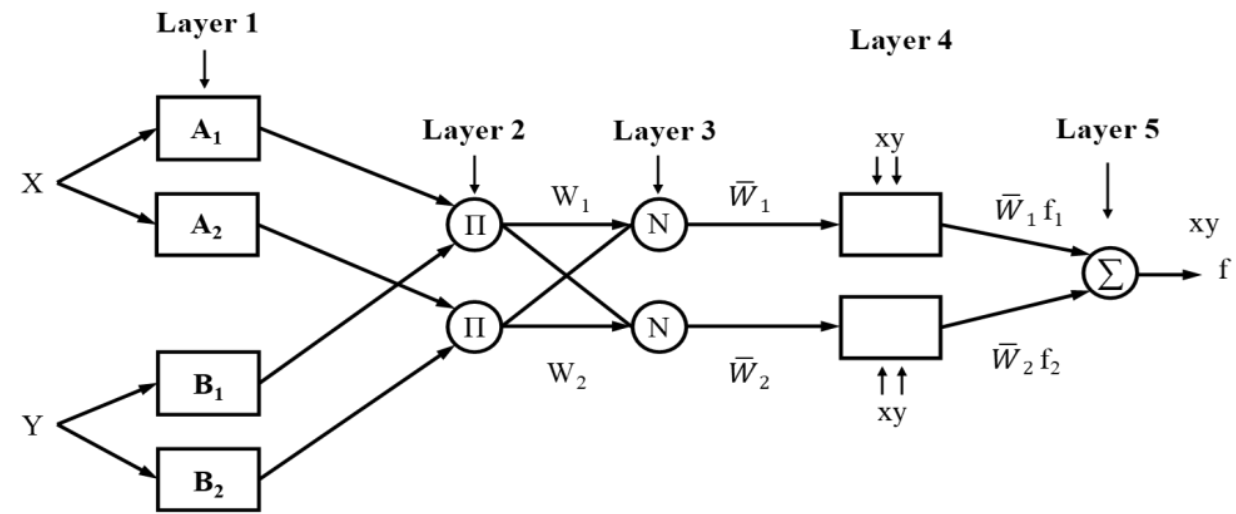

Figure 4. ANFIS architecture [9]

\section{RESULTS}

The results of steady-state and SLGF operation of a test case (without PC) is as shown in Figure 5.

The test system consists of three phases (R, S, T) represented with red, green and blue colors respectively. The simulated results of the test case of ungrounded system with SLGF on red phase (R) depicts the values of current on RST and faulted phase i.e. i3RST and i3R respectively before and after fault. Where number ' 3 ' in i3RST and i3R represents number of feeder i.e. $3^{\text {rd }}$ feeder. The fault current of i3R is more than 3 times of the sound phases i.e. equal to $650 \mathrm{~A}$.

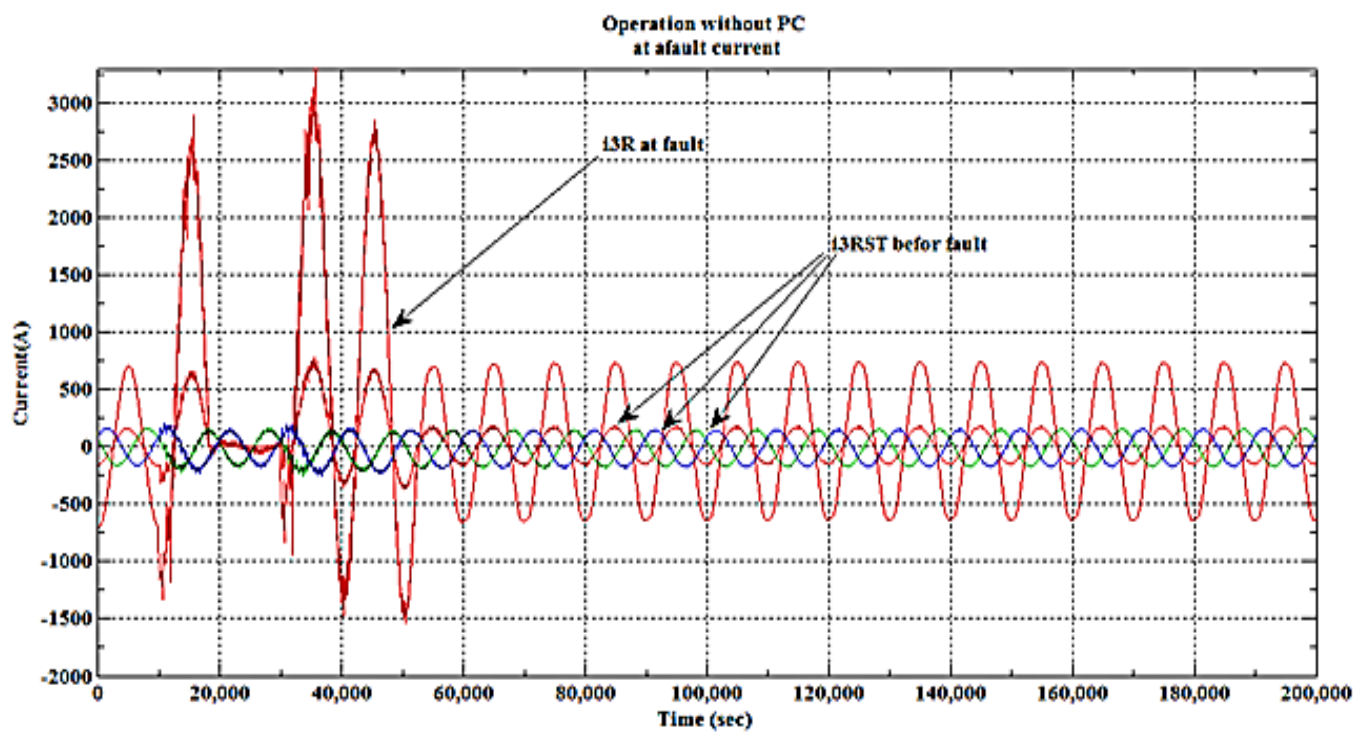

Figure 5. Results of a test case with SLGF without any control

The test case connected through PC was simulated and the corresponding results of the current of faulted phase (i3R) and current of sound phases (i3S, i3T) in a state of fault current controlled through PC are depicted in Figure 6. 


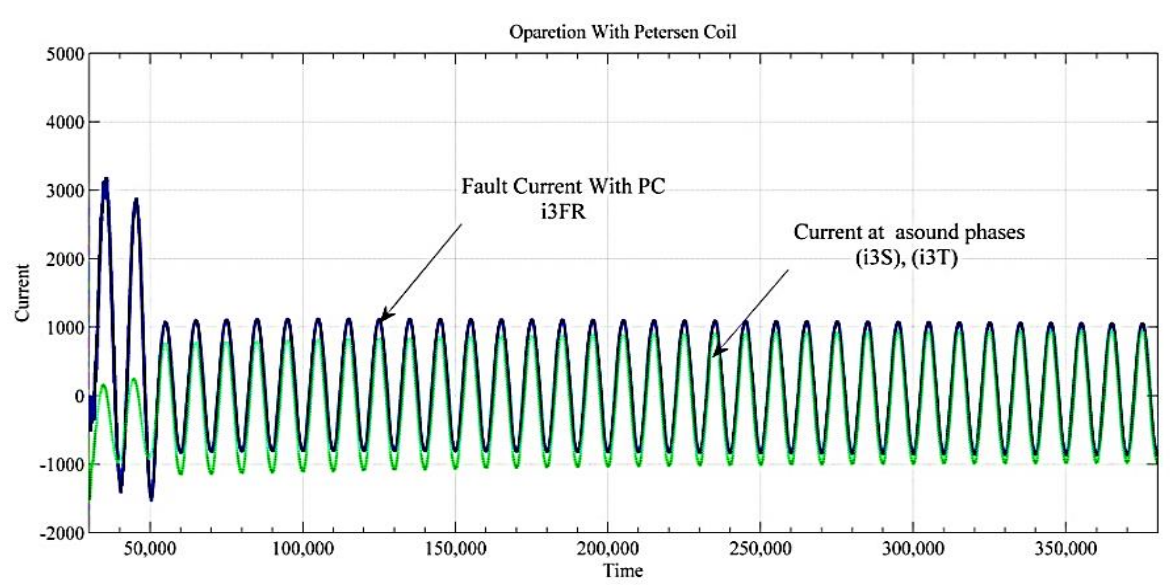

Figure 6. Results of a test case with SLGF controlled through PC

The results of a test case with SLGF causing capacitance, without and with applying ANFIS are shown in Figure 7 and Figure 8 respectively.

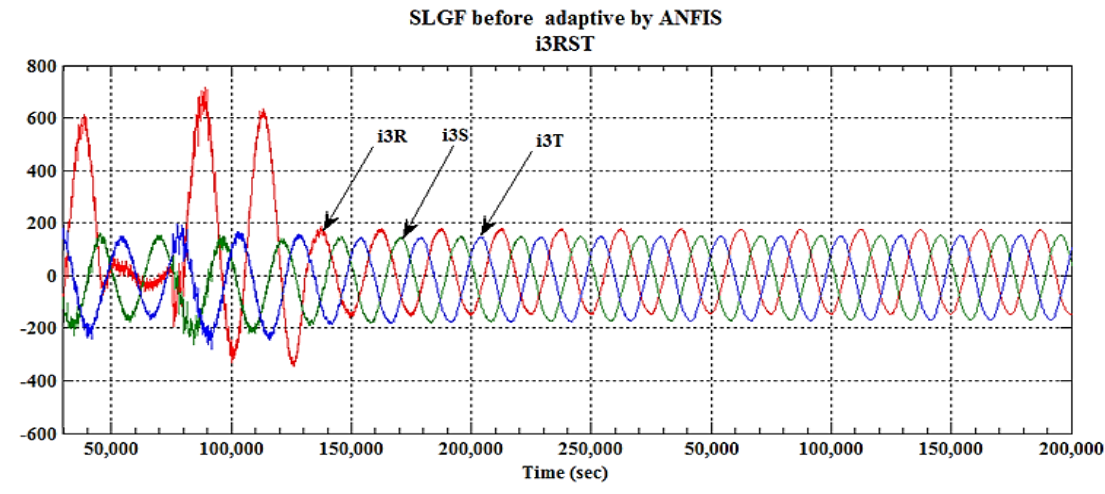

Figure 7. Results of a test case with SLGF before applying ANFIS

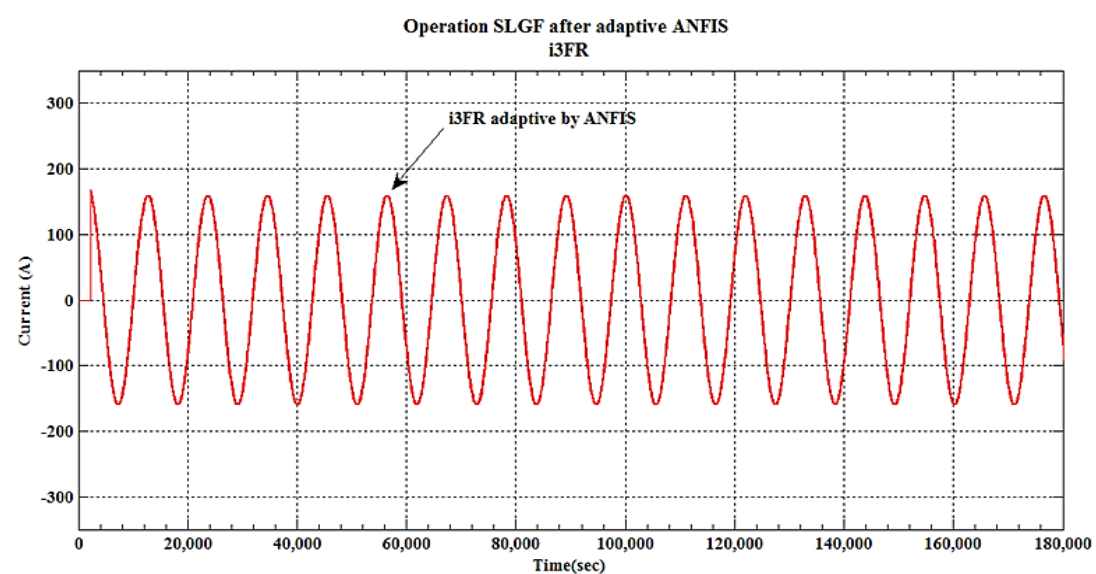

Figure 8. Results of a fault current i3R after applying ANFIS in a test case with SLGF

The current in a faulted red phase i3R after applying ANFIS results approximately same as the rated current of other live phases, which is equal to $150 \mathrm{~A}$. 
Validation of the achieved results was made by comparing with the PC controlled through PID. Its results are shown in Figure 9.

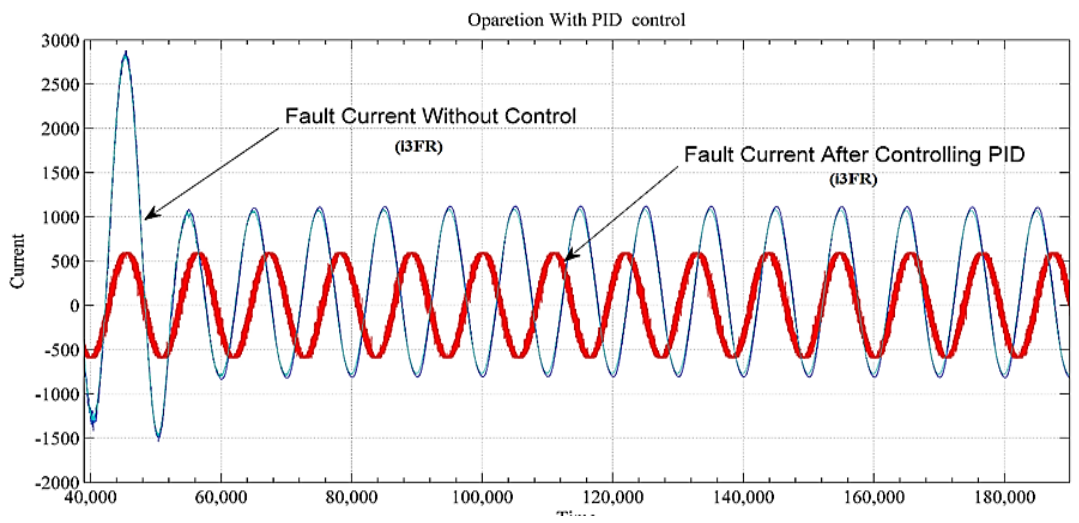

Figure 9. Results of a faulted current i3R with SLGF controlled without and with PID controller

Figure 10 represents the comparison of results of the faulted current i3R control without and with PC, PID and ANFIS.

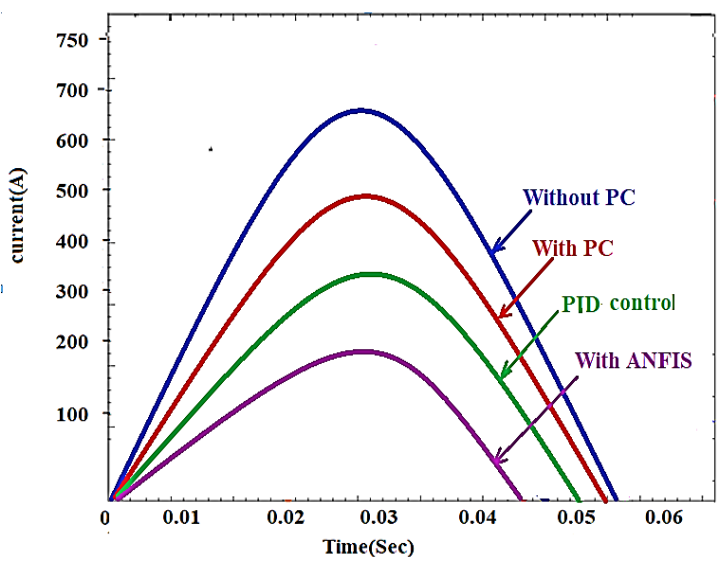

Figure 10. Comparison of results for the faulted current i3R without \& with the control of PC and with PID and ANFIS control

It represents the relationship of fault current $\mathrm{i} 3 \mathrm{R}$ in terms of amplitude and time. In the event of SLGF without use of PC, the fault current reaches to maximum i.e. more than 650A in 0.03 seconds, and lasts $0.057 \mathrm{sec}$ to reach 0. Comparatively, with PC only, PID control and ANFIS control, it reduces to $500 \mathrm{~A}, 300 \mathrm{~A}$ and almost $150 \mathrm{~A}$ respectively. The time taken to 0 also reduces to $0.056 \mathrm{sec}, 0.05 \mathrm{sec}$ and $0.045 \mathrm{sec}$ respectively.

\section{CONCLUSION}

In this paper, we investigated the reduction of the fault current during SLGF by using different methods. The methods included PC, PID and ANFIS control. The test case used, was modified IEEE 33/11 $\mathrm{kV}$ distribution system (with real parameters from Babylon Power Station Ltd, Iraq). As a tool Simulink/Matlab was used. The obtained results show the achievement of proposed method thus by reducing the fault current from $650 \mathrm{~A}$ in SLGF case to $150 \mathrm{~A}$, the nominal value as of live phases. Moreover, time taken to reach 0 value was also reduced from $0.065 \mathrm{sec}$ to $0.045 \mathrm{sec}$. 


\section{REFERENCE}

[1] R. Liang, X. Xue and C. Wang, "Peterson coils based on magnetic control adjustable reactance and its application," In IEEE International Conference on Automation and Logistics, ICAL 2008, pp. 1551-1555, 2008.

[2] J. Huang, X. Lin, and H. Liu, "An adaptive technique of earth fault detection and self-extinguishing by controllable Petersen-coil," Asia-Pacific Power Energy Eng. Conf. APPEEC, APPEEC.2011.5748647, pp. 1-4, 2011.

[3] Purva Sharma, Deepak Saini, Akash Saxena, "Fault Detection and Classification in Transmission Line Using Wavelet Transform and ANN", Bulletin of Electrical Engineering and Informatics, Vol. 5, No. 3, pp. 284-295, 2016.

[4] M. Loos, S. Werben, M. Kereit and J.-C Maun, "Fault direction method in compensated network using the zero sequence active energy signal," in 2013. IEEE EUROCON, 2013.

[5] S. J. Schwarz, "Analytical Expressions for the Resistance of Grounding Systems," Trans. Am. Inst. Electr. Eng. Part IIIPower Appar. Syst., vol. 73, no. 2, pp. 1011-1016, 1954.

[6] N. A. Yusof, H. Mohd Rosli, H. Mokhlis, M. Karimi, J. Selvaraj, and N. M. Sapari, "A new under-voltage load shedding scheme for islanded distribution system based on voltage stability indices," IEEJ Transactions on Electrical and Electronic Engineering, vol. 12, pp. 665-675, 2017.

[7] X. Zeng, K. K. Li, W. L. Chan, and S. Su, "Grounding faulted feeder detection with fault resistance measurement in mining power systems," Conf. Rec. - IAS Annu. Meet. IEEE Ind. Appl. Soc., vol. 1, pp. 657-661, 2005.

[8] F. B. Costa, A. Monti, and S. C. Paiva, "Overcurrent Protection in Distribution Systems with Distributed Generation Based on the Real-Time Boundary Wavelet Transform," IEEE Trans. Power Deliv, vol. 32, no. 1, pp. 462-473, 2017.

[9] J. M. Oliver and W. W. Eberhardt, "Operating Performance of a Petersen Earth Coil" Transactions of the American Institute of Electrical Engineers, Vol, XLV, pp.165-168, 1926.

[10] E. E. Hassan, T. K. A. Rahman, Z. Zakaria, N. Bahaman, M.H. Jifri, "Maximum Loadability Enhancement with a Hybrid Optimization Method," Bulletin of Electrical Engineering and Informatics, Vol 7, No 3, pp.323-330, 2018.

[11] V. C. Nikolaidis, E. Papanikolaou, and A. S. Safigianni, "A Communication-Assisted Overcurrent Protection Scheme for Radial Distribution Systems with Distributed Generation," IEEE Trans. Smart Grid, pp. 1-1, 2015.

[12] Yanqiu Bi, Jianguo Zhao, and Dahai Zhang, "Single-phase-to-ground fault feeder detection based on transient current and wavelet packet," 2004 Int. Conf. Power Syst. Technol. 2004. PowerCon, vol. 1, no. November, pp. 936940, 2004.

[13] Y. Wang, Y. Huang, X. Zeng, G. Wei, J. Zhou, T. Fang, and H. Chen, "Faulty feeder detection of single phaseearth fault using grey relation degree in resonant grounding system," IEEE Trans. Power Deliv., vol. 32, no. 1, pp. 55-61, 2017.

[14] Stuart Bennett, "Development of the PID controller", IEEE Control Systems Magazine, Volume 13, Issue 6, pp. 5865, 1993.

[15] Y. LI, K.H. ANG, and G.C. CHONG, "PID Control System Analysis and Design", IEEE Control Systems Magazine, Volume 26, Issue 1, pp. 32-41, 2006.

[16] Bhaskara Rao. Yenugula, Md. Zia-ur-Rahman, "Stability Control Structure of Hovercraft Prototype Utilizing PID Controller," Bulletin of Electrical Engineering and Informatics, Vol 6, No 4, pp.350-348, 2017.

[17] Gayathri Vijayachandran and B. K. Mathew, "High impedance arcing fault detection in MV networks using discrete wavelet transform and Artificial Neural Networks," in Green Technologies (ICGT), 2012 International Conference on, Trivandrum, Kerala, India, 18-20 Dec. 2012, pp. 089-098, 2012.

[18] K. Lenin, "Integrated Algorithm for Decreasing Active Power Loss," IAES Int. J. Artif. Intell., vol. 7, no. 1, pp. 3341,2018

[19] Muhammad Firdaus Shaari, Ismail Musirin, Muhamad Faliq Mohamad Nazer, Shahrizal Jelani, Farah Adilah Jamaludin, Mohd Helmi Mansor, A.V. Senthil Kumar, "Supervised evolutionary programming based technique for multi-DG installation in distribution system," IAES Int. J. Artif. Intell. vol. 9, no. 1, pp. 11-17, 2020.

[20] Xingwang Huang, Xuewen Zeng, Rui Han and Xu Wang, "An enhanced hybridized artificial bee colony algorithm for optimization problems," IAES Int. J. Artif. Intell. vol. 8, no. 1, pp. 87-94, 2019.

[21] A. Taalab and M. El-Geziry, "Impact of load variations on arcing fault detection in LV distribution networks," Dev. Power Syst., Conference Paper, Electronic ISBN: 978-1-84919-212-5, July 2010 .

[22] S. H. Michalik, M., Lukowicz, M., Rabizant, W., Lee, S.J., Kang, "New ANN-based algorithms for detecting HIFs in multi grounded MV networks," IEEE Trans. Power Deliv, vol. 23, no. 1, pp. 58-66, 2008.

[23] Swetapadma Panigrahi, Amarnath Thakur, "Modeling and simulation of three phases cascaded H-bridge grid-tied PV inverter," Bulletin of Electrical Engineering and Informatics, Vol 8, No 1, pp.1-9, 2019.

[24] D. M. Soomro, S. C. Chong, Z. A. Memon, F. Abbasi, "Power Quality Improvement in QUCEST Larkana Campus by Using Three Types of Power Filters", IJPEDS International Journal of Power Electronics and Drive Systems, Vol.8, No.4, pp.1876-1885, 2017.

[25] M. H. Lokman, "Multi-Verse Optimization Based Evolutionary Programming Technique for Power Scheduling in Loss Minimization Scheme," IAES Int. J. Artif. Intell. vol. 8, no. 3, pp. 292-298, 2019. 